\title{
Arsenic is associated with reduced effect of folic acid in myelomeningocele prevention: a case control study in Bangladesh
}

\author{
Maitreyi Mazumdar ${ }^{1,2^{*}}$, Md Omar Sharif Ibne Hasan ${ }^{3}$, Rezina Hamid ${ }^{4}$, Linda Valeri ${ }^{5}$, Ligi Paul ${ }^{6}$, Jacob Selhub ${ }^{6}$, \\ Ema G Rodrigues ${ }^{1,2}$, Fareesa Silva', Selim Mia ${ }^{3}$, Md Golam Mostofa ${ }^{3}$, Quazi Quamruzzaman ${ }^{3}$, Mahmuder Rahman ${ }^{3}$ \\ and David C Christiani ${ }^{2}$
}

\begin{abstract}
Background: Arsenic induces neural tube defects in several animal models, but its potential to cause neural tube defects in humans is unknown. Our objective was to investigate the associations between maternal arsenic exposure, periconceptional folic acid supplementation, and risk of posterior neural tube defect (myelomeningocele) among a highly exposed population in rural Bangladesh.

Methods: We performed a case-control study that recruited physician-confirmed cases from community health clinics served by Dhaka Community Hospital in Bangladesh, as well as local health facilities that treat children with myelomeningocele. Controls were selected from pregnancy registries in the same areas. Maternal arsenic exposure was estimated from drinking water samples taken from wells used during the first trimester of pregnancy. Periconceptional folic acid use was ascertained by self-report, and maternal folate status was further assessed by plasma folate levels measured at the time of the study visit.

Results: Fifty-seven cases of myelomeningocele were identified along with 55 controls. A significant interaction was observed between drinking water inorganic arsenic and periconceptional folic acid use. As drinking water inorganic arsenic concentrations increased from 1 to $25 \mu \mathrm{g} / \mathrm{L}$, the estimated protective effect of folic acid use declined (OR 0.22 to 1.03), and was not protective at higher concentrations of arsenic. No main effect of arsenic exposure on myelomeningocele risk was identified.
\end{abstract}

Conclusions: Our study found a significant interaction between drinking water inorganic arsenic concentration from wells used during the first trimester of pregnancy and reported intake of periconceptional folic acid supplements. Results suggest that environmental arsenic exposure reduces the effectiveness of folic acid supplementation in preventing myelomeningocele.

Keywords: Arsenic, Neural tube defect, Myelomeningocele, Birth defect, Folate deficiency

\section{Background}

Neural tube defects are debilitating birth defects characterized by high rates of mortality and lifelong disabilities in surviving children. Neural tube defects occur when the neural plate fails to fold in the first 3 to 4 weeks of gestation, causing death or permanent damage to the

\footnotetext{
* Correspondence: maitreyi.mazumdar@childrens.harvard.edu

'Department of Neurology, Boston Children's Hospital, 300 Longwood Avenue, Boston, MA, USA

2Department of Environmental Health, Harvard School of Public Health, 665 Huntington Avenue, Boston, MA, USA

Full list of author information is available at the end of the article
}

spinal cord [1]. Neural tube defects are among the most common birth defects worldwide, and their prevalence varies from 5.3 per 10,000 live births in the United States [2] to more than 10 per 1,000 pregnancies in certain areas of China [3]. This variance likely reflects differing contributions from risk factors such as prevalence of obesity and diabetes, nutritional status, usage of folic acid supplementation and/or folic acid fortification of the food supply, genetic susceptibility, and the presence of environmental toxicants. Although studies have identified numerous risk factors, these account for less than 
half of all neural tube defects, suggesting that additional genetic and environmental risk factors remain to be identified [4].

Of particular concern is environmental exposure to arsenic, which induces neural tube defects (exencephaly, spina bifida occulta) in several animal models, including mouse [5], rat [6], hamster [7], and chick [8]. Animal studies have demonstrated that arsenic crosses the placenta and preferentially accumulates in the neuroepithelium of developing hamster, mouse, and monkey embryos [9]. The potential mechanisms of arsenic-induced neural tube defects include direct toxicity from reactive oxygen species to the developing neural plate [8], and disruption of maternal glucose metabolism [10]. In addition, folate deficiency may exacerbate arsenic toxicity. Arsenic metabolism is catalyzed by enzymes that require S-adenosylmethionine (SAM) as the methyl donor. SAM is eventually regenerated via a process that requires 5-methyltetrahydrofolate as a cofactor. Thus, arsenic metabolism is dependent on the folate supply. The associations between folate and arsenic toxicity have been intensively studied in recent years. In mouse models, mice with specific defects in folate transport had higher rates of neural tube defects after in utero arsenic exposure than wild-type mice similarly exposed [5,11]. Understanding the associations between arsenic and folate is particularly important for public health practitioners as folic acid supplementation and fortification is the primary strategy for neural tube defect prevention. In addition to preventing neural tube defects, folic acid is recognized to reduce the risk of other congenital anomalies, with the strongest evidence supporting folic acid's role in reduction of cardiac malformations [12].

Exposure to arsenic through drinking water sources from groundwater is a global public health emergency that is particularly devastating in Bangladesh. According to survey data from 2000 to 2010, an estimated 35 to 77 million people in the country have been chronically exposed to arsenic in their drinking water in what has been described as the largest mass poisoning in history [13]. The most recent survey of wells (2010) reported that $42 \%$ of the water samples tested in Bangladesh had inorganic arsenic levels exceeding the World Health Organization drinking water guideline of $10 \mu \mathrm{g} / \mathrm{L}$, and $27 \%$ had levels that exceeded the Bangladesh guideline of $50 \mu \mathrm{g} / \mathrm{L}$. Many areas the inorganic arsenic concentrations in drinking water exceeded $1000 \mu \mathrm{g} / \mathrm{L}$ [14].

This study aimed to identify whether environmental arsenic exposure is associated with higher risk of neural tube defects, and whether environmental arsenic exposure modifies the protective effect of folic acid supplementation. No data are available on the incidence and prevalence of neural tube defects in Bangladesh due to the country's lack of a systematic surveillance system for birth defects, although these malformations are fairly common in clinical practices [15]. We therefore conducted a case-control study that established a new case ascertainment system. We administered a protocol that measured inorganic arsenic concentrations in drinking water from sources used during the first trimester of pregnancy.

\section{Methods}

\section{Study population}

This case-control study was conducted between April and November 2013 in the communities served by Dhaka Community Hospital (DCH) in Bangladesh. The unstable political situation in Bangladesh in November 2013 required the termination of the study after enrolling 57 of the planned 60 cases and 55 of the planned 60 controls. DCH operates community health centers throughout rural areas of Bangladesh, many of which are located within regions that are high priorities for arsenic remediation projects by the Bangladeshi government and by nongovernmental organizations. The case ascertainment system we established included regular communication between $\mathrm{DCH}$ and district and union health officials, health centers, and midwives in the Pabna, Barisal, Rajshahi, Munshiganj, and Chittagong Districts, as well as referral from local hospitals (Dhaka Community Hospital, Bangladesh Medical College, Dhaka Shishu Hospital, and Bangabandhu Sheikh Mujib Medical University). Eligible cases were infants and children under age 1 year with myelomeningocele.Infants affected by anterior neural tube defects (e.g. anencephaly) were not included, as they were not expected to be reliably identified using our strategy. Most births in these areas occur at home, and the birth of infants who die soon after delivery, as is expected for infants with anencephaly, is often not reported.

To confirm case diagnoses, a pediatrician with expertise in classifying neural tube defects (O.S.I.) performed a physical examination or, if the subject was deceased, reviewed photographs. Pregnancy registries from $\mathrm{DCH}-$ affiliated health centers that were located in the same areas as the cases served as the source of controls. Controls were matched (1:1) by sex and age using the following method: potential controls were separated into groups corresponding to sex and birth quarter, and placement on the list of potential controls was assigned by random digit assignment. Once a case was enrolled, potential controls were approached in order of assignment on the list. Participation was $98 \%$ among potential cases and $83 \%$ among potential controls. Reasons for refusal to participate were similar between cases and controls, including the lack of desire to participate in any studies and the fear that giving blood will cause sickness. Our a priori power estimate was that our pilot study 
sample size would provide $82 \%$ power if the true odds ratio for myelomeningocele in infants exposed to high levels of arsenic relative to low was 3.5. For this estimate, we defined high-level arsenic exposure as levels within the top quartile of observed; we assumed a correlation coefficient between cases and controls of 0.2 and a Type I error of 0.05 .

Informed consent was provided by parents before enrollment. The Human Research Committees at Boston Children's Hospital $(\mathrm{BCH})$ and at $\mathrm{DCH}$ approved this study.

\section{Questionnaires and medical history}

Trained interviewers asked parents about their medical histories, including the use of medications during pregnancy, family history, water consumption, and reproductive history. Periconceptional folic acid supplementation was defined as reporting any intake of a folic acidcontaining supplement before within the two months prior to awareness of the pregnancy. Nutritional intake of mothers was assessed using a food frequency questionnaire previously validated in rural Bangladeshi populations [16]. Children underwent a physical examination including evaluation for level of neural tube defect and presence of other congenital abnormalities.

\section{Arsenic exposure from drinking water}

At the time of enrollment, a water sample was collected from the tube well each mother identified as her primary source of drinking water at the time when she became aware of her pregnancy. Water samples were collected in $50 \mathrm{ml}$ polypropylene tubes (BD Falcon, BD Bioscience, Bedford, MA), preserved with Reagent Grade nitric acid (Merck, Germany) to a $\mathrm{pH}<2$, and stored at room temperature. Arsenic analysis was conducted by using inductively coupled plasma mass-spectrometry (ICP-MS) following US EPA method 200.8 (Spectrum Analytical, Inc., Agawam, MA USA). For quality control, instrument performance was validated by a spiked laboratory control sample (ICP, Analytical Mixture 12 Solution A, HighPurity Standards, Charleston, SC USA) with percent recoveries ranging from $98 \%$ to $107 \%$. Of the 112 samples included in this analysis, 45 (41.2\%) had an inorganic arsenic concentration below the $0.15 \mu \mathrm{g} / \mathrm{L}$ limit of detection (LOD). These samples were reassigned half the value of the LOD for statistical analyses. Families found to have drinking water inorganic arsenic concentrations $\geq 50 \mu \mathrm{g} / \mathrm{L}$ (Bangladesh standard) were advised to seek alternative drinking water.

\section{Blood collection and processing}

Maternal blood samples were collected via venipuncture into two EDTA tubes and transported in an insulated container to Dhaka within one day of collection, after which they were stored at $-20^{\circ} \mathrm{C}$. Blood was centrifuged and plasma collected into microcentrifuge tubes and stored at $-20^{\circ} \mathrm{C}$. Blood/plasma samples were shipped to HSPH on dry ice.

\section{Folate analysis}

Folate analyses were performed at the Vitamin Metabolism Laboratory at the Jean Mayer USDA Human Nutrition Research Center at Tufts University. We measured total folate of the plasma samples by microbial assay with the use of Lactobacillus casei [17]. We serially diluted $5 \mu \mathrm{L}$ of each plasma sample and plated the samples in triplicate onto a 96-microtiter well plate with $150 \mu \mathrm{L}$ of $L$. casei growth medium. We incubated the plates overnight in a $37^{\circ} \mathrm{C}$ humid incubator and measured the absorbance, which indicated microbial growth, with the use of a 96-well plate reader (PowerWave HT; BioTek Instruments Inc, Winooski, VT USA) at $595 \mathrm{~nm}$. To test if any arsenic in plasma affected the microbial assay, we spiked 3 random samples with $5 \mathrm{ng} / \mathrm{mL}$ folic acid, and there were no inhibitory components detected in the plasma. The coefficients of variation for the assay using one plasma sample with high folate concentration and one sample with low folate concentration were $6.78 \%$ and $4.73 \%$, respectively.

\section{Statistical analysis}

Data were analyzed using SAS (version 9.3; SAS Institute, Inc. Cary, NC USA). We used unconditional logistic regression to calculate crude and adjusted odds ratios (ORs) as well as $95 \%$ confidence intervals (CI). We did not use conditional models because of the uneven numbers of cases and controls, but instead forced the matching variables of child age and sex into all models, as strategy suggested by Rothman and Greenland $[18,19]$. Data exploration suggested that the log-odds of case identification varied exponentially with levels of inorganic arsenic in well water. Consequently, log-transformed inorganic arsenic concentration was treated as a continuous variable in regression models. Potential confounding factors for the main effect of water arsenic included smoking status of each parent, medication use, betel nut use, birth order, folic acid use, family history of congenital defect, use of pesticides during pregnancy, place of birth (home, birth center, or hospital), and report of undergoing an ultrasound during pregnancy - the latter two variables were considered additional measures of socioeconomic status.

We used inverse probability weighting (IPW) to correct locations that presented very different exposure profiles of our control populations, a method recently reviewed succinctly by Seaman and White [20]. A large percentage of our controls were drawn from Birhampur Community Clinic (BCC) and Sirajdikhan Community Clinic (SCC). BCC and SCC currently participate in 
other research activities conducted by our group; therefore, the population in those sites had a higher probability of selection as a control. Using IPW, each individual in the study population was given a sampling weight that was the inverse of the probability of selection, in this case the inverse of the proportion of controls from the site from which the control was recruited. We investigated effect modification with reported prenatal folic acid supplementation by using interaction terms in our weighted logistic regression models.

\section{Results}

The 57 cases of neural tube defects included 49 cases of lumbar and 8 cases of cervical myelomeningocele. None of the mothers reported alcohol consumption, smoking, betel nut use, or use of medications other than periconceptional folic acid supplements (all mothers denied use of anticonvulsant drugs) during pregnancy. None of the mothers reported a diagnosis of diabetes, including gestational diabetes. Overall, 39.4\% of the study population reported periconceptional folic acid use, which is similar to other studies in Bangladesh [21]. As shown in Table 1, mothers of controls were younger than mothers of cases (23.1 years versus 25.2 years, $\mathrm{p}=0.02$ ). Mothers of controls were more likely to report periconceptional folic acid use than mothers of cases $(71 \%$ versus $49 \%, \mathrm{p}=$ 0.02). Plasma folate concentrations were higher at the time of study visit among women who reported periconceptional folic acid use (Mean $12.7 \mathrm{nmol} / \mathrm{L}$ vs. $7.4 \mathrm{nmol} /$ $\mathrm{L}, \mathrm{p}=0.02$ ). Plasma folate concentrations were not significantly different between mothers of controls and mothers of cases (Mean $10.6 \mathrm{nmol} / \mathrm{L}$ vs. $10.5 \mathrm{nmol} / \mathrm{L}$, $\mathrm{p}=0.97)$.

Differences in median drinking water arsenic concentration were observed. Controls had higher drinking water inorganic arsenic concentrations, though this appeared to be due to the contribution of controls from one site only, Birhampur Community Clinic (BCC) in Pabna $(n=22)$. Data exploration showed that controls from sites aside from BCC had lower median water arsenic concentrations than cases (Table 2).

In adjusted models, drinking water inorganic arsenic concentration collected from wells that were used during the first trimester of pregnancy was not significantly associated with risk of myelomeningocele. In models that tested the interaction between water inorganic arsenic concentrations and periconceptional folic acid use, however, the interaction was statistically significant (Table 3). Using the parameters derived from our logistic regression model, the estimated OR for periconceptional folic acid use demonstrates a decrease in the protective effect of folic acid $(\mathrm{OR}=0.22,95 \% \mathrm{CI}[0.13,0.37]$ at $1 \mu \mathrm{g} / \mathrm{L}$ drinking water inorganic arsenic; $\mathrm{OR}=1.03,95 \% \mathrm{CI}$ $[0.55,1.91])$ at $25 \mu \mathrm{g} / \mathrm{L}$ drinking water inorganic arsenic) (Figure 1).

\section{Discussion}

Our study found a significant interaction between drinking water inorganic arsenic concentration from wells used during the first trimester of pregnancy and reported intake of perinatal folic acid supplements. As drinking water inorganic arsenic concentrations increased from $1 \mu \mathrm{g} / \mathrm{L}$ to $25 \mu \mathrm{g} / \mathrm{L}$, the estimated protective

Table 1 Characteristics of cases of myelomeningocele and controls in Bangladesh (mean \pm SD, except where noted)

\begin{tabular}{|c|c|c|c|}
\hline Characteristic & Controls $(n=55)$ & Cases $(n=57)$ & $p$ Value \\
\hline Age (months) & $8.0 \pm 4.9$ & $5.9 \pm 5.3$ & 0.38 \\
\hline Male [n (\%)] & $32(58)$ & $34(60)$ & 0.87 \\
\hline Mother's age at delivery (years) & $23.1 \pm 4.1$ & $25.2 \pm 5.4$ & 0.02 \\
\hline Father's age at delivery (years) & $31.5 \pm 5.4$ & $32.5 \pm 6.8$ & 0.38 \\
\hline Reported prenatal folic acid use [n(\%)] & $39(71)$ & $28(49)$ & 0.02 \\
\hline First born & $25(46)$ & $23(40)$ & 0.56 \\
\hline Cesarian section $[n(\%)]$ & $24(44)$ & $23(40)$ & 0.72 \\
\hline Birth site & & & 0.15 \\
\hline Hospital & $23(22)$ & $14(25)$ & \\
\hline Birth center/clinic & $11(20)$ & $15(26)$ & \\
\hline Home & $24(44)$ & $28(49)$ & \\
\hline Reported any ultrasound during pregnancy $[\mathrm{n}(\%)]$ & $50(91)$ & $48(92)$ & 0.19 \\
\hline Plasma folate concentration (nmol/L) & $10.6 \pm 14.7$ & $10.5 \pm 13.8$ & 0.97 \\
\hline \multicolumn{4}{|l|}{ Level of neural tube defect } \\
\hline Lumbar [n (\%)] & & $49(86)$ & \\
\hline Cervical [n (\%)] & & $8(14)$ & \\
\hline
\end{tabular}


Table 2 Distribution of water inorganic arsenic concentrations

\begin{tabular}{llll}
\hline & Controls & $\begin{array}{l}\text { Controls } \\
\text { excluding BCC }\end{array}$ & Cases \\
\hline First trimester drinking water $(\mu \mathrm{g} / \mathrm{L})$ & & & 53 \\
$\mathrm{n}$ & 55 & $38.3 \pm 101.6$ & $19.8 \pm 54.6$ \\
Mean $\pm \mathrm{SD}$ & $49.4 \pm 103.6$ & $<\mathrm{LOD}^{2}$ & 0.7 \\
Median & 6.9 & $<\mathrm{LOD}$ & $<\mathrm{LOD}$ \\
25th percentile & $<\mathrm{LOD}$ & 8.5 & 12.7 \\
75 th percentile & 54.9 & $<\mathrm{LOD}$ & $<\mathrm{LOD}$ \\
Lowest & $<\mathrm{LOD}$ & 450.0 & 357.0 \\
Highest & 506.0 & & \\
\hline
\end{tabular}

${ }^{1} \mathrm{BCC}=$ Birhampur Community Clinic.

${ }^{2} \mathrm{LOD}=$ limit of detection $(0.15 \mu \mathrm{g} / \mathrm{L})$.

effect of folic acid use declined (OR $=0.22,95 \%$ CI [0.13, $0.37]$ to $\mathrm{OR}=1.03,95 \% \mathrm{CI}[0.55,1.91])$. This finding suggests that environmental arsenic exposure reduces the effectiveness of folic acid supplementation in preventing neural tube defects.

Our study is the first in humans to demonstrate that environmental arsenic exposure influences risk of myelomeningocele. At minimum, this study demonstrates that there is a need for surveillance for neural tube defects among populations with high environmental arsenic exposure, and that additional preventive strategies may be required in these areas. On a wider scale, the combination of folate deficiency and arsenic poisoning in Bangladesh may be a setting for an unrecognized epidemic of neural tube defects.

Few studies have investigated the relationship between arsenic exposure during pregnancy and risk of neural tube defects in humans. Most recently, archeological studies in an area of northern Chile characterized by high environmental arsenic levels have shown that the prevalence of spina bifida occulta among mummies was $13.5 \%$, compared with $2.4 \%$ in a low-arsenic area believed to have had no other differences in diet or other factors [22]. Investigation of a cluster of anencephalic births near the Texas-Mexico border found that maternal and paternal exposures to arsenic were associated with higher risk of neural tube defects, but this finding was not statistically significant [23]. In Bangladesh, a study of the pregnancy outcomes of 2006 women who regularly consumed drinking water with high arsenic concentration found that there was a small but statistically significant association (OR: 1.005, 95\% CI: 1.000-1.010) between arsenic exposure and congenital anomalies, though the study did not specify the nature of these anomalies [24]. During an ecological study in China's Yangtze River Delta region, the arsenic content of the soil in 40 towns and 80 villages was associated with frequency of congenital anomalies, including neural tube defects [25]. Critiques of the epidemiological literature have noted that human studies of arsenic and neural tube defects have been limited by lack of individual measures of exposure and by lack of measures of exposure during the critical period of early gestation [26].

Table 3 Results from weighted logistic regression models with the outcome neural tube defects $(n=112)$

\begin{tabular}{|c|c|c|c|c|c|c|}
\hline \multirow[t]{2}{*}{ Variable } & \multicolumn{3}{|c|}{ Main effects model } & \multicolumn{3}{|c|}{ Interaction model } \\
\hline & $\beta$ & OR $(95 \% \mathrm{Cl})^{1}$ & pValue & $\beta$ & OR $(95 \% \mathrm{Cl})^{1}$ & $p$ Value \\
\hline Ln-water As & 0.0278 & $1.03(0.96,1.11)$ & 0.45 & -0.3190 & - & - \\
\hline Periconceptional folic acid use ${ }^{2}$ & -1.2029 & $0.300(0.19,0.47)$ & $<0.0001$ & 1.7280 & - & - \\
\hline Home birth ${ }^{3}$ & 0.9224 & $2.51(1.61,3.92)$ & $<0.0001$ & 1.0047 & $2.73(1.72,4.32)$ & $<0.0001$ \\
\hline Mother's age in years & 0.1649 & $1.18(1.10,1.26)$ & $<0.0001$ & 0.1573 & $1.17(1.09,1.26)$ & $<0.0001$ \\
\hline Father's age in years & -0.0607 & $0.94(0.89,1.00)$ & 0.05 & -0.0416 & $0.96(0.90,1.01)$ & 0.17 \\
\hline Child sex ${ }^{4}$ & 0.9152 & $2.50(1.56,3.99)$ & 0.0001 & 0.7986 & $2.22(1.38,3.59)$ & 0.001 \\
\hline Child age in months & -0.1305 & $0.88(0.84,0.92)$ & $<0.0001$ & -0.1337 & $0.88(0.94,0.91)$ & $<0.0001$ \\
\hline Ln-water As*prenatal folic acid use & & & & 0.4636 & - & $<0.0001$ \\
\hline
\end{tabular}

${ }^{1}$ OR indicates odds of being a CASE.

${ }^{2}$ Reported use $=1$, No reported use $=0$.

${ }^{3}$ Home birth $=1$, Clinic or Hospital birth $=0$.

${ }^{4}$ Male $=1$, Female $=0$. 


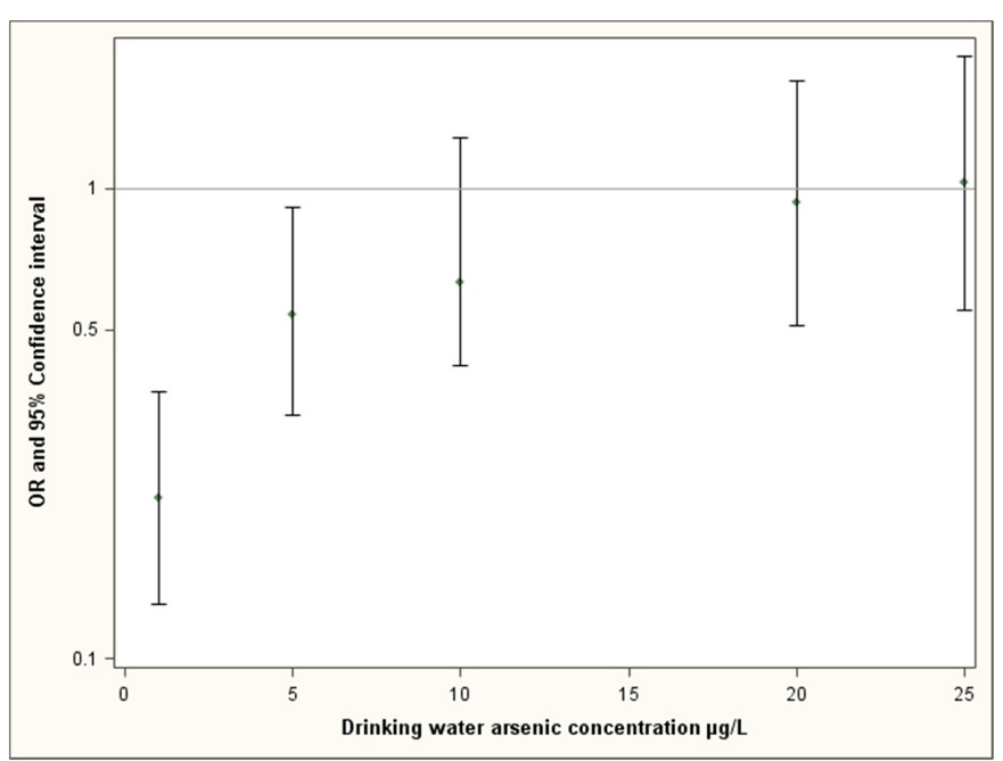

Figure 1 The predicted odds ratio of periconceptional folic acid use and myelomeningocele from the interaction model at various distributions of inorganic arsenic concentration in drinking water. Average (mean) values of parental age, child age, child sex and home birth were used to estimate odds ratios.

The strengths of our study include the use of individual measures of exposure, including measurements of the drinking water from wells that mothers identified as their source of water at the time they became aware of their pregnancy-a time point that is very close to the crucial time point in neural tube defect pathogenesis. Our interviews with community members indicated a frequent practice for women to return to their parents' homes in the months around childbirth, therefore we were careful to identify the exact well used during the first trimester. Though the drinking water was collected from the identified wells approximately one year after the onset of pregnancy, arsenic concentrations have been shown to be stable over a one year time period, with the most recent study in Araihazar, Bangladesh, demonstrating variability of $10 \%$ to $30 \%$ in well samples collected every 2 to 4 weeks over a period of 3 years [27]. In our study, drinking water inorganic arsenic concentration was used as a proxy for in utero arsenic concentration, and drinking water arsenic concnetration may not accurately reflect the internal arsenic dose encountered by the developing embyro. Previous studies in humans support placental transfer of arsenic; studies of pregnant women in Argentina and Bangladesh have shown that the arsenic concentration in cord blood is similar to that in maternal blood $[28,29]$.

Another reason our study may have found associations is that the arsenic concentrations in our study were much higher than those observed in other studies. For example, among controls in the 2006 cluster casecontrol study conducted along the Texas/Mexico border, less than $2 \%$ of women were found to have inorganic arsenic concentrations greater than $10 \mu \mathrm{g} / \mathrm{L}$ in drinking water [23], whereas in this study the drinking water inorganic arsenic concentration was greater than $10 \mu \mathrm{g} / \mathrm{L}$ in $55.5 \%$ of controls, and the maximum drinking water arsenic concentration $(506 \mu \mathrm{g} / \mathrm{L})$ was over 50 times that threshold.

An additional strength of our study is that we minimized the potential recall bias by validating folic acid use reports with biomarkers. This comparison has considerable limitations, as we were only able to measure plasma folate after pregnancy. Ours is the first study in Bangladesh to measure plasma folate concentrations among mothers of children with neural tube defects, and we can infer from the strong correlation between the two measures that women who reported periconceptional folic acid use have more access to folate containing foods and/or folic acid supplements. Nevertheless, the potential for recall bias is inherent in all retrospective studies and is an important limitation of this study.

Folate is the centerpiece of the one-carbon metabolism pathway that has a key role in reactions that are important in many key biological processes including synthesis of DNA, and for the generation of methyl groups used in a multitude of important reactions. Arsenic is metabolized in humans through sequential addition of methyl groups acquired from the one-carbon metabolism pathway. In trials, folic acid supplementation has been shown to reduce total blood arsenic concentrations by increasing the methylation of inorganic arsenic into less toxic species [30]. One possible explanation for the observed interaction 
between arsenic and folic acid supplementation is that arsenic depletes the supply of methyl donors necessary for reactions important in normal neural tube development.

Arsenic may also increase the risk for neural tube defects by disruption of maternal glucose homeostasis. Two well-established risk factors for neural tube defects are maternal gestational diabetes and prepregnancy obesity [31-36]. Accumulating evidence has shown an increase risk of type 2 diabetes in general populations exposed to arsenic [37-39], and there is growing evidence that pregnant women also experience increase risk of dysregulated glucose homeostasis with arsenic exposure [40]. Although the mechanisms underlying the risks of gestational diabetes remain unclear, there is evidence from experimental models that in utero hyperglycemia can cause excess generation of reactive oxygen species due to mitochondrial dysfunction [41] and activation of programmed cell death (apoptotic) signaling cascades [42]. None of the women in our study reported a diagnosis of gestational diabetes, but subclinical alterations in glucose regulation due to arsenic toxicity are likely to be present, and may play a role in modulating risk of neural tube defects.

Though the interaction between water arsenic concentration and reported folic acid use was highly significant, our study did not demonstrate a significant primary (or main) effect of drinking water arsenic concentrations on myelomeningocele risk. This is most likely because our pilot study was underpowered, though it is also possible that even higher arsenic exposures are needed to demonstrate a primary effect. Another potential explanation is that our study was designed to identify myelomeningocele at the time of birth or presentation to medical care; a surveillance system following all pregnancies might have identified a more severe phenotype. Infants with arsenic-induced neural tube defects may have died during gestation, or were otherwise undiscovered. Another possible explanation for why we did not find a main effect of arsenic exposure comes from the multifactorial threshold model of neural tube defects that posits that neural tube defects result from an additive contribution of several risk factors, which are each individually insufficient to disrupt neural tube closure [43]. Despite our attempts to adjust for confounding and selection bias, residual differences between the study groups and study sites are still possible, and thus, more detailed collection of important covariates including socioeconomic status, nutritional intake and folate status is needed in future studies.

Our findings raise important questions about the risk of neural tube defects in arsenic-endemic areas and the effectiveness of folic acid supplements. Larger, prospective studies with more refined measures of folic acid supplementation and folate status of mothers are needed.

\section{Conclusions}

Environmental arsenic exposure may reduce the protective effects of folic acid supplementation in high exposure areas, such as Bangladesh. More surveillance for neural tube defects is needed in arsenic endemic areas. Additional preventive measures, such as higher doses of folic acid, as well as early detection and management of maternal diabetes, may be needed in areas with high levels of environmental arsenic exposure.

\section{Abbreviations}

DCH: Dhaka community hospital; LOD: Limit of detection; IPW: Inverse probability weighting; BCC: Birhampur community clinic; SCC: Sirajdikhan community clinic.

\section{Competing interests}

The authors declare they have no competing interests.

\section{Authors' contributions}

MM, OSI, RH, FS, QQ and DCC designed research. MM, OSI, LP, JS, EGR, SM, MGM, QQ and MR conducted research. MM, LV and DCC performed statistical analyses. MM, LP, LV and DCC wrote the paper. MM had primary responsibility for final content. All authors read and approved the final manuscript.

\section{Acknowledgements}

Funding for this study was provided by the Child Neurology Foundation and the Harvard School of Public Health NIEHS Center (ES000002). Dr. Mazumdar was supported by a Mentored Career Development Award from the NIEHS, National Institutes of Health (K23 ES017437). Additional support was provided by NIEHS grant P42 ES16454.

We thank the study staff at Dhaka Community Hospital including Biplop Biswas and Md Sohel Rana, who conducted field visits. Li Su supervised laboratory work at HSPH. We thank the Boston Children's Hospital Clinical Research Center (CRC) for their assistance. Kimberly Chin from the CRC prepared and managed the REDCap database. Senior statisticians Al Ozonoff and Kush Kapur prepared randomization protocols for participation selection. Shaye Moore and Elizabeth Jarvis provided editorial assistance.

\section{Author details}

'Department of Neurology, Boston Children's Hospital, 300 Longwood Avenue, Boston, MA, USA. ${ }^{2}$ Department of Environmental Health, Harvard School of Public Health, 665 Huntington Avenue, Boston, MA, USA. ${ }^{3}$ Dhaka Community Hospital, 190/1 Baro Moghbazar, Wireless Railgate, Dhaka 1217, Bangladesh. ${ }^{4}$ Bangladesh Medical College, 14/A Dhanmondi, Dhaka 1209, Bangladesh. ${ }^{5}$ Department of Biostatistics, Harvard School of Public Health, 655 Huntington Avenue, Boston, MA, USA. ${ }^{6}$ Jean Mayer USDA Human Nutrition Research Center on Aging, Tufts University, 711 Washington Street, Boston, MA, USA.

Received: 5 January 2015 Accepted: 20 March 2015

Published online: 10 April 2015

\section{References}

1. Volpe JJ. Neurology of the newborn. 5th ed. Philadelphia: Saunders/Elsevier; 2008.

2. Williams J, Mai CT, Mulinare J, Isenburg J, Flood TJ, Ethen M, et al. Updated estimates of neural tube defects prevented by mandatory folic Acid fortification - United States, 1995-2011. MMWR Morb Mortal Wkly Rep. 2015:64(1):1-5.

3. Li Z, Ren A, Zhang L, Ye R, Li S, Zheng J, et al. Extremely high prevalence of neural tube defects in a 4-county area in Shanxi Province, China. Birth Defects Res A Clin Mol Teratol. 2006;76(4):237-40.

4. Agopian AJ, Tinker SC, Lupo PJ, Canfield MA, Mitchell LE. National birth defects prevention S: proportion of neural tube defects attributable to known risk factors. Birth Defects Res A Clin Mol Teratol. 2013;97(1):42-6.

5. Hill DS, Wlodarczyk BJ, Finnell RH. Reproductive consequences of oral arsenate exposure during pregnancy in a mouse model. Birth Defects Res B Dev Reprod Toxicol. 2008;83(1):40-7. 
6. Beaudoin AR. Teratogenicity of sodium arsenate in rats. Teratology. 1974;10(2):153-7.

7. Carpenter SJ. Developmental analysis of cephalic axial dysraphic disorders in arsenic-treated hamster embryos. Anat Embryol. 1987;176(3):345-65.

8. Han ZJ, Song G, Cui Y, Xia HF, Ma X. Oxidative stress is implicated in arsenic-induced neural tube defects in chick embryos. Int J Dev Neurosci. 2011:29(7):673-80

9. Hanlon DP, Ferm VH. Placental permeability of arsenate ion during early embryogenesis in the hamster. Experientia. 1977;33(9):1221-2.

10. Hill DS, Wlodarczyk BJ, Mitchell LE, Finnell RH. Arsenate-induced maternal glucose intolerance and neural tube defects in a mouse model. Toxicol Appl Pharmacol. 2009;239(1):29-36.

11. Wlodarczyk BJ, Zhu H, Finnell RH. Mthfr gene ablation enhances susceptibility to arsenic prenatal toxicity. Toxicol Appl Pharmacol. 2014;275(1):22-7.

12. Feng $Y$, Wang $S$, Chen $R$, Tong $X$, Wu Z, Mo X. Maternal folic Acid supplementation and the risk of congenital heart defects in offspring: a meta-analysis of epidemiological observational studies. Sci Rep. 2015;5:8506

13. Smith $A H$, Lingas EO, Rahman M. Contamination of drinking-water by arsenic in Bangladesh: a public health emergency. Bull World Health Organ. 2000;78(9):1093-103.

14. Chakraborti D, Rahman MM, Das B, Murrill M, Dey S, Chandra Mukherjee S, et al. Status of groundwater arsenic contamination in Bangladesh: a 14-year study report. Water Res. 2010;44(19):5789-802.

15. Dey AC, Shahidullah M, Mannan MA, Noor MK, Saha L, Rahman SA. Maternal and neonatal serum zinc level and its relationship with neural tube defects. J Health Popul Nutr. 2010;28(4):343-50.

16. Chen Y, Ahsan H, Parvez F, Howe GR. Validity of a food-frequency questionnaire for a large prospective cohort study in Bangladesh. Br J Nutr. 2004;92(5):851-9.

17. Horne DW, Patterson D. Lactobacillus casei microbiological assay of folic acid derivatives in 96-well microtiter plates. Clin Chem. 1988;34(11):2357-9.

18. Rothman KJ, Greenland S. Matching. In: Rothman KJ, Greenland S, editors. Modern Epidemiology. 2nd ed. New York: Lippincott, Williams \& Wilkins; 1998. p. 147-61.

19. Rothman KJ, Greenland S. Introduction to Regression Modelling. In: Rothman KJ, Greenland S, editors. Modern Epidemiology. 2nd ed. New York: Lippincott, Williams \& Wilkins; 1998. p. 401-34.

20. Seaman $S R$, White IR. Review of inverse probability weighting for dealing with missing data. Stat Methods Med Res. 2013;22(3):278-95.

21. Baqui AH, El-Arifeen S, Darmstadt GL, Ahmed S, Williams EK, Seraji HR, et al. Effect of community-based newborn-care intervention package implemented through two service-delivery strategies in Sylhet district, Bangladesh: a clusterrandomised controlled trial. Lancet. 2008;371(9628):1936-44.

22. Silva-Pinto V, Arriaza B, Standen V. [Spina bifida occulta associated with environmental arsenic exposure in a prehispanic sample from northern Chile]. Rev Med Chil. 2010;138(4):461-9.

23. Brender JD, Suarez L, Felkner M, Gilani Z, Stinchcomb D, Moody K, et al. Maternal exposure to arsenic, cadmium, lead, and mercury and neural tube defects in offspring. Environ Res. 2006;101(1):132-9.

24. Kwok RK, Kaufmann RB, Jakariya M. Arsenic in drinking-water and reproductive health outcomes: a study of participants in the Bangladesh Integrated Nutrition Programme. J Health Popul Nutr. 2006;24(2):190-205.

25. Wu J, Chen G, Liao Y, Song X, Pei L, Wang J, et al. Arsenic levels in the soil and risk of birth defects: a population-based case-control study using GIS technology. J Environ Health. 2011;74(4):20-5.

26. DeSesso JM. Teratogen update: inorganic arsenic. Teratology. 2001;64(3):170-3.

27. Dhar RK, Zheng $Y$, Stute $M$, van Geen $A$, Cheng Z, Shanewaz M, et al. Temporal variability of groundwater chemistry in shallow and deep aquifers of Araihazar, Bangladesh. J Contam Hydrol. 2008:99(1-4):97-111.

28. Concha G, Vogler G, Nermell B, Vahter M. Low-level arsenic excretion in breast milk of native Andean women exposed to high levels of arsenic in the drinking water. Int Arch Occup Environ Health. 1998;71(1):42-6.

29. Hall M, Gamble M, Slavkovich V, Liu X, Levy D, Cheng Z, et al. Determinants of arsenic metabolism: blood arsenic metabolites, plasma folate, cobalamin, and homocysteine concentrations in maternal-newborn pairs. Environ Health Perspect. 2007:115(10):1503-9.

30. Gamble MV, Liu X, Slavkovich V, Pilsner JR, llievski V, Factor-Litvak P, et al. Folic acid supplementation lowers blood arsenic. Am J Clin Nutr. 2007:86 (4):1202-9.

31. Shaw GM, Todoroff $K$, Finnell RH, Lammer EJ. Spina bifida phenotypes in infants or fetuses of obese mothers. Teratology. 2000;61(5):376-81.
32. Watkins ML, Rasmussen SA, Honein MA, Botto LD, Moore CA. Maternal obesity and risk for birth defects. Pediatrics. 2003;111(5 Pt 2):1152-8.

33. Soler NG, Walsh CH, Malins JM. Congenital malformations in infants of diabetic mothers. Q J Med. 1976;45(178):303-13.

34. Waller DK, Shaw GM, Rasmussen SA, Hobbs CA, Canfield MA, Siega-Riz AM, et al. Prepregnancy obesity as a risk factor for structural birth defects. Arch Pediatr Adolesc Med. 2007;161(8):745-50.

35. Hendricks KA, Nuno OM, Suarez L, Larsen R. Effects of hyperinsulinemia and obesity on risk of neural tube defects among Mexican Americans. Epidemiology. 2001;12(6):630-5.

36. Werler MM, Louik C, Shapiro S, Mitchell AA. Prepregnant weight in relation to risk of neural tube defects. JAMA. 1996;275(14):1089-92.

37. Pan WC, Seow WJ, Kile ML, Hoffman EB, Quamruzzaman Q, Rahman M et al. Association of low to moderate levels of arsenic exposure with risk of type 2 diabetes in Bangladesh. Am J Epidemiol. 2013;178(10):1563-70.

38. Kuo CC, Moon K, Thayer KA, Navas-Acien A. Environmental chemicals and type 2 diabetes: an updated systematic review of the epidemiologic evidence. Curr Diab Rep. 2013;13(6):831-49.

39. Maull EA, Ahsan H, Edwards J, Longnecker MP, Navas-Acien A, Pi J, et al. Evaluation of the association between arsenic and diabetes: a national toxicology program workshop review. Environ Health Perspect. 2012;120 (12):1658-70.

40. Ettinger AS, Zota AR, Amarasiriwardena CJ, Hopkins MR, Schwartz J, Hu H, et al. Maternal arsenic exposure and impaired glucose tolerance during pregnancy. Environ Health Perspect. 2009;117(7):1059-64.

41. Zangen SW, Yaffe P, Shechtman S, Zangen DH, Ornoy A. The role of reactive oxygen species in diabetes-induced anomalies in embryos of Cohen diabetic rats. Int J Exp Diabetes Res. 2002;3(4):247-55.

42. Yang P, Li X, Xu C, Eckert RL, Reece EA, Zielke HR, et al. Maternal hyperglycemia activates an ASK1-FoxO3a-caspase 8 pathway that leads to embryonic neural tube defects. Science signaling. 2013;6(290):ra74.

43. Harris MJ, Juriloff DM. Mouse mutants with neural tube closure defects and their role in understanding human neural tube defects. Birth Defects Res A Clin Mol Teratol. 2007;79(3):187-210.

\section{Submit your next manuscript to BioMed Central and take full advantage of:}

- Convenient online submission

- Thorough peer review

- No space constraints or color figure charges

- Immediate publication on acceptance

- Inclusion in PubMed, CAS, Scopus and Google Scholar

- Research which is freely available for redistribution 